\title{
Importance of two-dimensional strain imaging in diagnosis of coronary artery disease
}

\author{
DOI: https://doi.org/10.32007/med.1936/jfacmedbagdad.v60i4.1 \\ Ahmed M. Hussein * FIBMS, CABMS \\ Mahdi S. Alzaidi ** $\quad$ FIBMS \\ Bashar M. Abed *** FIBMS
}

(9) (9)

This work is licensed under a Creative Commons Attribution-NonCommercial 4.0 International License.

\begin{abstract}
:
JFac Med Baghdad

2018; Vol.60, No .4

Received: Oct. 2018

Accepted: Mar. 2019

Published: May,2019

Background: Strain imaging assessing regional myocardial deformation and can be used to quantify regional myocardial function and differentiate between ischemic and non ischemic myocardium.

Objectives: to assess sensitivity and specificity of strain imaging in detection of coronary artery disease in comparison with coronary angiography.

Patients and Methods: ninety six patients were referred to Ibn albitar center for cardiac surgery, Baghdad, Iraq with symptoms of coronary artery disease for a period between June 2014 and April 2015, all of whom were evaluated by two dimensional echocardiography and all were found to have good left ventricular systolic function with no regional wall motion abnormalities (RWMA), coronary angiography were done for all patients.

Results: of the 96 patients: 69(71.9\%) were males and 27(28.1\%) females, with mean age $55.7 \pm 9.71$ years. Thirty-one (32.3\%) patients have no significant coronary artery disease and sixty-five $(67.7 \%)$ have significant coronary artery disease. The sensitivity and specificity of global longitudinal strain in detection of coronary artery disease are $67.7 \%$ and $80.6 \%$ respectively. Global longitudinal strain appears to be useful in localization of coronary artery disease.

Conclusions: speckle tracking Strain echocardiography is simple, noninvasive and non-angle dependent with acceptable sensitivity and specificity in early detection of cardiomyopathy including ischemic myopathy.

Key words: strain image, speckle, coronary artery disease.
\end{abstract}

\section{Introduction:}

Echocardiography is one of the most widely used cardiac imaging in patients with suspected coronary artery disease (CAD) and it is excellent for assessment of left ventricular function $(1,2)$. However, conventional echocardiography may not show regional wall motion abnormality (RWMA) at rest (3). Echocardiographic strain imaging (deformation) have emerged as a quantitative technique to accurately estimate myocardial contractility and function (4). strain of specific myocardial region can be defined by the change in length divided by the original length expressed by the formula: strain $=\Delta \mathrm{L} / \mathrm{L} 0$, where $\Delta \mathrm{L}=$ change in length, and $\mathrm{LO}=$ original length (5). The amount of deformation (positive or negative strain) is usually expressed in percentage (6).

* Dept. of Medicine, Ninevah college of medicine, University of Ninevah, Corresponding Auther: Email: ah1977mo@gmail.com.

$\begin{array}{lll}* * & \text { Ibn albitar } & \text { cardiac center. } \\ \text { mahdizaidi@yahoo.com. } & & \text { cardiac } \\ \text { *** } & \text { Maysan } & \text { center }\end{array}$

drbasharmuhamad75@gmail.com.
Speckle tracking is a post-processing computer algorithm that uses the routine grayscale digital images. The interaction of ultrasound with the myocardium produces unique acoustic patterns, or "speckles." These speckles can be tracked over time and speckle displacement used to calculate tissue velocity and strain (7) The advantages of this technique includes being angle independent (because it is not based on the Doppler principle) (8), semiautomated (as speckle tracking is automated) and allows the generation of bull's eye plots of longitudinal segmental strain. (9)

Standard models of left ventricular (LV) segmentation have been used to facilitate a more detailed analysis of regional LV function. The use of the 17-myocardial segment model has been recommended by the American Society of Echocardiography and American Heart Association (fig 1) (10). Subendocardial segment (containing longitudinally orientated myocardial fibers) are most susceptible to ischemia (11), for this reason measurements of longitudinal strain may be the most sensitive markers of CAD using tissue Doppler imaging (TDI) (12) or 2-dimensional strain echocardiography (2DSE) (13). 


\section{PLAX View and Corresponding Coronary SI}

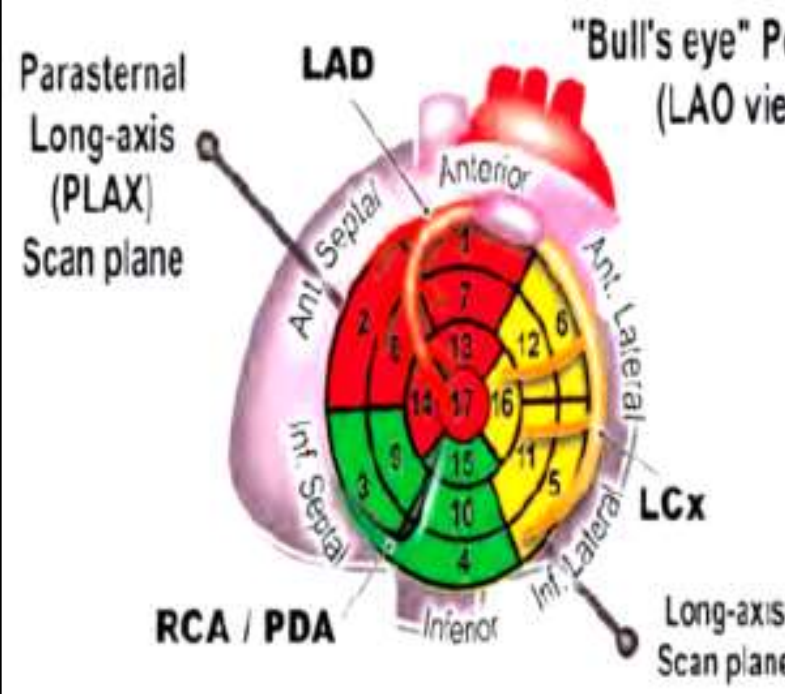

Fig. 1: LV segments and the corresponding coronary artery territories. (10)

\section{Patients and methods:}

Study populations: from June 2014 to April 2015, a 96 patients referred to Ibn-Albitar center for cardiac surgery with symptoms suggestive of coronary artery disease. Those patients were evaluated by detailed history with assessment of risk factors, clinical examination, echocardiography, routine laboratory tests (complete blood count, renal function test and viral screen) and coronary angiography. All patients have no RWMA with normal left ventricular ejection fraction (LVEF\%) by $2 \mathrm{D}$ echocardiography. Patients with Atrial fibrillation or multiple ventricular ectopic beats, significant valvular heart disease, left ventricular systolic dysfunction or poor image acquisition were excluded from the study.

\section{Echocardiographic examination:}

Echocardiographic examinations were performed using a Philips iE33 system (Bothell WA, USA) with a S5-1 transducer. Examination include measurements of cardiac dimensions and LV EF\% and analyzed according to American Heart Association recommendations.

Speckle tracking strain echocardiography was performed using apical four chambers, threechambers, and two chambers views for the segmental and global longitudinal strain (LS). All images were obtained at a frame rate of $60-100$ frames/s. Three consecutive cardiac cycles were saved in digital format. Strain analysis was done using Philips Q lab CMQ analysis. automated algorithm provided the segmental longitudinal strain in bull's eye display (Figure 2).

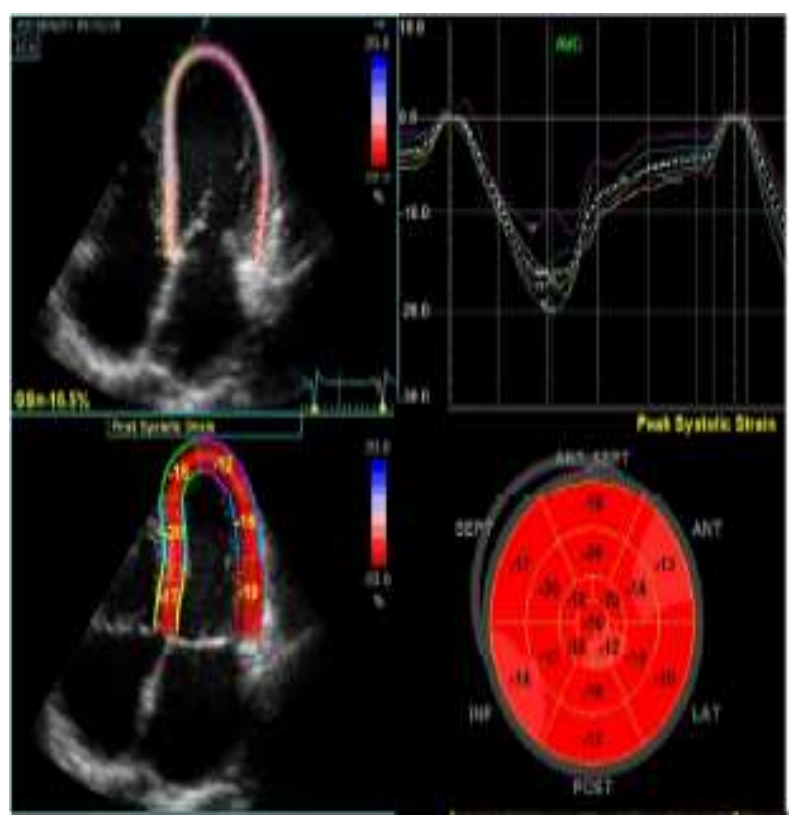

Fig 2: longituidinal strain curves from the apical 4-chamber view with accompanying bulls-eye plot. (14)

Global longitudinal strain (GLS) was defined as an average value of the 17 segmental longitudinal strains of an LV. Then strain values for each coronary vessels are calculated by calculating the average results of the segments supplied by that vessel as shown in fig. 1. Longitudinal strain results (GLS and segmental LS) more than the normal range mentioned by HUNT study ( $-17.4 \%$ for women and $-15.9 \%$ for men) are regarded abnormal.(15)

Coronary angiography: were visually assessed for all coronary lesions in two orthogonal planes. We assessed the number of affected vessels, using a cutoff of percent diameter stenosis $\geq 70 \%$ for three epicardial vessels and $\geq 50 \%$ for left main (LM) coronary artery (16)

Statistical analysis: Statistical analysis was performed using SPSS software (version 19). Data are presented as means \pm standard deviation, sensitivity and specificity. The Chi-square test or Fisher's exact test was used to compare variables. P. value $<0.05$ regarded as a significant value. 


\section{Results:}

Table 1: Demographic and Clinical of the patients:

\begin{tabular}{ll}
\hline Age (year) & $55,7 \pm 9.7(\mathrm{y})$ \\
\hline Gender, $\mathrm{n}(\%)$ & $69(71.9 \%)$ \\
Male & $27(28.1 \%)$ \\
Female & $69(71.9 \%)$ \\
\hline Hypertension, n(\%) & $34(35.4 \%)$ \\
\hline DM, n(\%) & $43(44.8 \%)$ \\
\hline Smoking, n(\%) & \\
\hline Presentation, n(\%) & $57(59.4 \%)$ \\
Stable angina & $39(40.6 \%)$ \\
Acute coronary syndrome & $52(54.2 \%)$ \\
\hline Abnormal ECG, n(\%) & $61.7 \pm 8.09$ \\
\hline LV EF \%, mean \pm SD & $31(32.3 \%)$ \\
\hline Coronary angiography: n(\%) & $65(67.7 \%)$ \\
No Significant CAD: & $22(22.9 \%)$ \\
Significant CAD: & $23(24 \%)$ \\
1-vessel disease & $20(20.8 \%)$ \\
2-vessel disease & $43(44.8 \%)$ \\
3-vessel disease & \\
LAD stenosis & $39(40.6 \%)$ \\
LCX stenosis & $45(46.9 \%)$ \\
RCA stenosis & $5(5.2 \%)$ \\
LMS stenosis &
\end{tabular}

RCA: right coronary artery, LMS: left main stem

Table 2: relationship between clinical variables and strain echocardiography:

\begin{tabular}{|c|c|c|c|c|c|}
\hline \multirow{2}{*}{ Variable } & & \multicolumn{2}{|c|}{ Global longitudinal strain } & \multirow{2}{*}{ Total } & \multirow{2}{*}{ P. value } \\
\hline & & Normal & abnormal & & \\
\hline \multirow{2}{*}{ gender } & male & $35(50.7 \%)$ & $34(49.3 \%)$ & 69 & \multirow{2}{*}{0.92} \\
\hline & female & $14(51.8 \%)$ & $13(48.2 \%)$ & 27 & \\
\hline \multirow{2}{*}{ presentation } & ACS & $16(44.4 \%)$ & $23(55.6 \%)$ & 36 & \multirow{2}{*}{0.1} \\
\hline & Stable angina & $33(57.9 \%)$ & $24(42.1 \%)$ & 57 & \\
\hline \multirow{2}{*}{ ECG } & normal & $29(65.9 \%)$ & $15(34.1 \%)$ & 44 & \multirow{2}{*}{0.007} \\
\hline & abnormal & $20(38.4 \%)$ & $32(61.6 \%)$ & 52 & \\
\hline \multirow{2}{*}{ HT } & Not hypertensive & $15(55.5 \%)$ & $12(44.5 \%)$ & 27 & \multirow[t]{2}{*}{0.58} \\
\hline & hypertensive & $34(49.2 \%)$ & $35(50.8 \%)$ & 69 & \\
\hline \multirow{2}{*}{$\mathrm{DM}$} & Non diabetic & $39(62.9 \%)$ & $23(37.1 \%)$ & 62 & \multirow{2}{*}{0.002} \\
\hline & diabetic & $10(29.4 \%)$ & $24(70.6 \%)$ & 34 & \\
\hline
\end{tabular}

As shown in table 2 there is no association between gender and GLS $(\mathrm{P}$. value $=0.92)$. and no significant association differences in strain values between patients presented with acute coronary syndrome or stable angina $(P$. value $=0.1)$, forty-four patients have normal ECG and fifty two patients have ECG changes suggestive of IHD, of the latter 20 patients have normal strain study and 32 patients have abnormal strain results with $\mathrm{P}$. value $=0.007$. There was no statistically different results of strain study between hypertensive and nonhypertensive patients $(\mathrm{P}$. value $=0.58)$, but strain results appear to be more abnormal in diabetic patients in comparison with non diabetics with $\mathrm{p}$. value $=0.002$.
Table 3: The correlation between coronary angiography and results of global longitudinal strain in detection of CAD:

\begin{tabular}{|c|c|c|c|c|c|c|}
\hline & & \multicolumn{2}{|c|}{$\begin{array}{l}\text { Coronary } \\
\text { angiograph } \\
\text { y }\end{array}$} & \multirow[t]{2}{*}{$\begin{array}{l}\text { Sensitiv } \\
\text { ity }\end{array}$} & \multirow[t]{2}{*}{$\begin{array}{l}\text { Specifi } \\
\text { city }\end{array}$} & \multirow{2}{*}{$\begin{array}{l}\text { P. } \\
\text { valu } \\
\text { e }\end{array}$} \\
\hline & & $\begin{array}{l}\text { No } \\
\text { CA } \\
\text { D }\end{array}$ & $\begin{array}{l}\text { CA } \\
\text { D }\end{array}$ & & & \\
\hline \multirow{2}{*}{$\begin{array}{l}\text { Global } \\
\text { longitudi } \\
\text { nal } \\
\text { strain }\end{array}$} & Normal & 25 & 21 & \multirow{2}{*}{$67.7 \%$} & \multirow{2}{*}{$80.6 \%$} & \multirow{2}{*}{$\begin{array}{l}0.00 \\
01\end{array}$} \\
\hline & $\begin{array}{l}\text { Abnor } \\
\text { mal }\end{array}$ & 6 & 44 & & & \\
\hline Total & & 31 & 65 & & & \\
\hline
\end{tabular}


Thirty-one patients have no significant coronary artery lesions, of whome $25(80.6 \%)$ patients have normal GLS and $6(19.3 \%)$ have abnormal GLS. Sixty five patients have significant CAD lesions on coronary angiography: of whom $44(67.7 \%)$ patients had abnormal GLS study and 21(32.3\%) patients had normal GLS study. The sensitivity and specificity of GLS in detection of CAD are $67.7 \%$ and $80.6 \%$ respectively with $P$. value $=0.0001$.

Table 4: Significance of strain echocardiography in detection of myocardial ischemia in the territory of each coronary artery:

\begin{tabular}{lllll}
\hline \multirow{2}{*}{$\begin{array}{l}\text { Coronary } \\
\text { angiography results }\end{array}$} & \multicolumn{2}{l}{ Longitudinal strain } & P. value \\
\cline { 2 - 4 } & normal & abnormal & \\
\hline \multirow{2}{*}{ LAD } & No lesion & 49 & 3 & 0.0001 \\
\cline { 2 - 4 } & lesion & 14 & 30 & 0.0001 \\
\hline \multirow{2}{*}{ LCX } & No lesion & 45 & 12 & 0.0001 \\
\cline { 2 - 4 } & lesion & 7 & 33 & 0.028 \\
\cline { 2 - 4 } RCA & No lesion & 44 & 6 & \\
\hline LMS & lesion & 15 & 31 & 5 \\
\hline
\end{tabular}

Table 4 show that: After coronary angiography, Left main stem lesion found in 5 patients all of them have abnormal longitudinal strain $(P$. value $=0.028)$. forty-four patients $(45.8 \%)$ have LAD lesions, of whom 14 patients have normal longitudinal strain and 30 patients have abnormal longitudinal strain results ( $\mathrm{P}$. value $=0.0001)$. forty patients $(41.7 \%)$ have LCX lesion: 7 have normal longitudinal strain and 30 patients have abnormal longitudinal strain study $(\mathrm{P}$. value $=0.0001)$. forty-six $(47.9 \%)$ patients have RCA lesion: 15 patients have normal longitudinal strain and 31 patients have abnormal longitudinal strain $(\mathrm{P}$ value $=0.0001)$.

\section{Discussion:}

The visual interpretation of wall motion abnormality (WMA) by echocardiography is widely used in most laboratories for diagnosis of CAD depending on myocardial thickening and endocardial excursion. However, this approach is subjective, operator dependent, demands complete visualization of the endocardium and is subject to the effects of cardiac loading and heart rate (17). The current study found that higher global longitudinal strain values (more than $-17.4 \%$ in females and more than $-15.9 \%$ in males) was associated with high percentage of CAD on coronary angiography with a high sensitivity, specificity and significant $P$. values , this is similar to Sung Won Choi et al (18) who enrolled 273 patients with no RWMA: 179 patients with stable angina and 94 patients with ACS: He found that strain imaging demonstrates a strong correlation with coronary angiography and it has potential as a noninvasive diagnostic tool for detecting coronary artery stenosis. Hubbard et al
(19) also found a significant reduction in longitudinal strain and dys-synochrony in patients with coronary artery disease (proved by coronary angiography) compared with the control group. These differences remained significant after adjusting for other clinical variables, such as heart rate, LVEF, left ventricular hypertrophy, blood pressure and body surface area.

Diabetes mellitus appear to affect longitudinal strain study significantly as most of the patients with false positive GLS have DM, this is consistent with results of Kolesnyk(20) and Nakai et al(21) who found that subclinical LV longitudinal strain abnormalities are frequently observed in asymptomatic diabetes patients in whom glucose metabolism disorders adversely affect heart function, as evidenced by the decreased left ventricular longitudinal function.

The current study demonstrate that longitudinal strain study not only useful in diagnosis of CAD but also in localization of stenosed vessel, similar to Smedsrud et al (22) who found that Duration of early systolic lengthening was significantly increased in segments related to the significant stenosis compared with remote myocardial segments. Moustafa et al (23) found that segmental longitudinal strain showed statistical significance for localization of the affected vessel for LAD, LCX and RCA.

\section{Conclusion:}

Strain echocardiography as assessed by speckle tracking technique is simple, noninvasive, non angle dependent with acceptable sensitivity and specificity in early detection of coronary artery disease, it also useful in localization of coronary artery disease.

\section{Author's contribution:}

All authors contributed to the design, data collection, data analysis and writing of the final article.

\section{References:}

1- Al-Gharbawi HS, Saeed BN. Correlation Between Regional Wall Motion Abnormalities via 2Dimensional Echocardiography, and Coronary Angiographic Findings. The Iraqi postgraduate medical journal. 2012; vol 11:630-34.

2- Hassan AE, Mohammed NH, Al-Janabi HK, et al. Evaluation of left ventricular function in diabetics with ischemic heart disease. Fac Med Baghdad 2009; vol.51, N0.4.

3- Biering-Šrensen T, Hoffmann S, Mogelvang R, et al. Myocardial Strain Analysis by 2-Dimensional Speckle Tracking Echocardiography Improves Diagnostics of Coronary Artery Stenosis in Stable Angina Pectoris. Circulation Cardiovascular Imaging. 2014;7:58-65.

4- Gilman G, Khandheria BK, Hagen ME, et al. Strain rate and strain: $s$ step-by-step approach to image and data acquisition. Journal of American Society of Echocardiography. 2004;17:1011-20. 
5- Dandel M, Hetzer R. Echocardiographic strain and strain rate imaging-clinical applications. International Journal of Cardiology 2009;132:1124.

6- Brian D. Hoit, MD. Strain and Strain Rate Echocardiography and Coronary Artery Disease. Cardiovascular Imaging. 2011; 4: 179-190.

7- Leitman M, Lysyansky P, Sidenko S, et al. Twodimensional strain: A novel software for real-time quantitative echocardiographic assessment of myocardial function. Journal of American Society of Echocardiography. 2004;17:1021-1029.

8- Amundsen BH, Helle-Valle T, Edvardsen T, et al. Noninvasive myocardial strain measurement by speckle tracking echocardiography: validation against sonomicrometry and tagged magnetic resonance imaging. Journal of American College of Cardiology. 2006;47:789-793.

9- Abraham TP, Dimaano VL and Liang HY. Role of Tissue Doppler and Strain Echocardiography in Current Clinical Practice; Circulation.2007; 116:2597-2609.

10-Lang RM, Bierig $M$, Devereux RB, et al; Chamber Quantification Writing Group; American Society of Echocardiography's Guidelines and Standards Committee; European Association of Echocardiography. Journal of American Society of Echocardiography 2005; 18:1440-63.

11-Kadhim MA, Al-Marayati AN, Haji GF. Estimation of left ventricular ejection fraction using mitral annular displacement derived by speckle tracking echocardiography in patients with different heart diseases. Alkindy college medical journal. Vol. 11, no.2. page: $17-22$.

12-Hoffmann S, Mogelvang $R$, Sogaard $P$, et al. Tissue Doppler echocardiography reveals impaired cardiac function in patients with reversible ischaemia. European Journal of Echocardiography. 2011;12:628-634.

13-Shimoni S, Gendelman $G$, Ayzenberg $O$, et al. Differential effects of coronary artery stenosis on myocardial function: the value of myocardial strain analysis for the detection of coronary artery disease. Journal of American Society of Echocardiography. 2011;24:748-757.

14-Ersbül MK. Left ventricular global longitudinal strain in acute myocardial infarction. Danish Medical Journal 2013;60(8): B4697

15-Dalen H, Thorstensen A, Aase SA, et al. Segmental and global longitudinal strain and strain rate based on echocardiography of 1266 healthy individuals: the HUNT study in Norway. European Journal of Echocardiography. 2010 Mar;11(2):17683.

16-Hawas JM, Aldoori KM, Almayahi MH. Clinical and angiographic characteristics of left main coronary artery disease, A retrospective study. J Fac Med Baghdad, Vol. 49, No. 1, 2007.

17-Lang RM, Bierig $M$, Devereux RB, et al; American Society of Echocardiography's Nomenclature and Standards Committee; Task Force on Chamber Quantification; American College of Cardiology Echocardiography Committee; American Heart Association; European Association of Echocardiography, European Society of Cardiology. Recommendations for chamber quantification. European Journal of Echocardiography 2006; 7:79-108.

18-Choi SW, Cho KI, Lee HC, et al. Diagnostic Value of Ultrasound-Based Strain Imaging in Patients with Suspected Coronary Artery Disease. Korean Circulation Journal 2008;38:398-404.

19-Hubbard RT, Calle MCA, Barros-Gomes S, et al. 2-Dimensional speckle tracking echocardiography predicts sever coronary artery disease in women with normal left ventricular function: a case-control study. BMC Cardiovascular Disorders (2017) 17:231.

20-Kolesnyk MY. Speckle tracking echocardiography in hypertensive males with glucose metabolism disorders, Zaporizhzhia State Medical University. Запорожский медицинский журнал. - 2014. - № 6 (87). - C. 4-10.

21-Nakai H, keuchi MT, Nishikage T, et al. Subclinical left ventricular dysfunction in asymptomatic diabetic patients assessed by twodimensional speckle tracking echocardiography: correlation with diabetic duration. European Journal of Echocardiography (2009) 10,926 - 932. 22-Smedsrud MK, Sarvari S, Huagaa KH. et al, Duration of Myocardial Early Systolic Lengthening Predicts the Presence of Significant Coronary Artery Disease. jacc. 2012 Sep 18;60(12):1086-93.

23-Moustafa SH, Elrabat KH, Swailem F, et al. The correlation between speckle tracking echocardiography and coronary artery disease in patients with suspected stable angina pectoris. Indian Heart Journal 70 (2018): 379-386. 


\section{أهمية تصوير إلاجهادِ ثنائي الابعاد في تثخيصِ أمراضِ الثرايينِ التاجٍِِ}

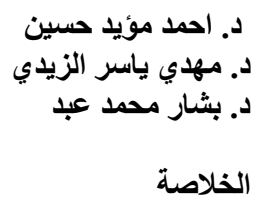

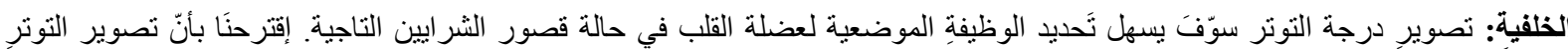

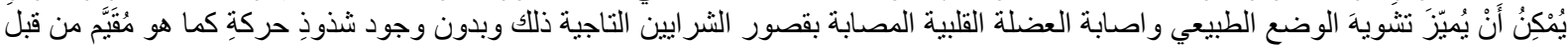
فحص صدى القلب التقليدي.

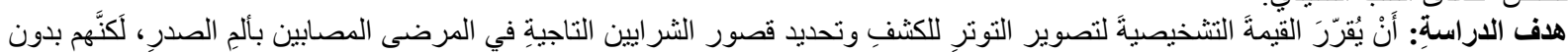

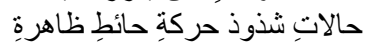

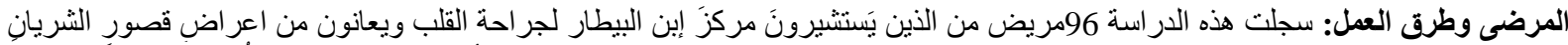

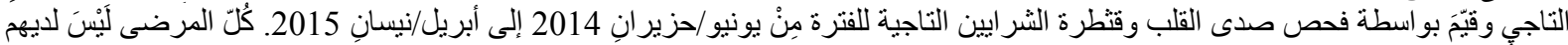

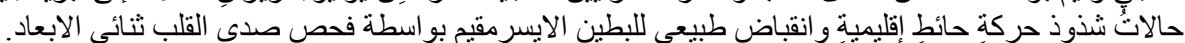

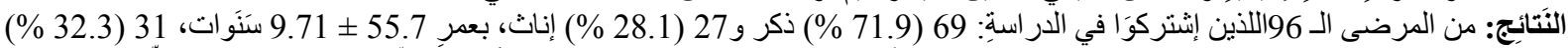

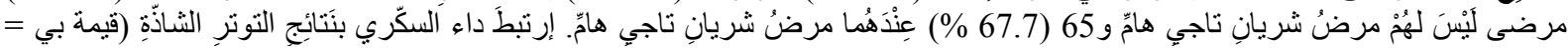

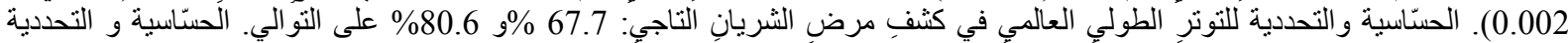

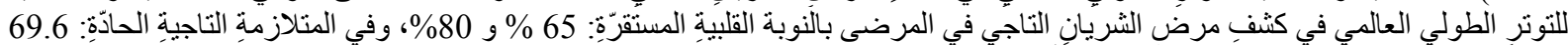

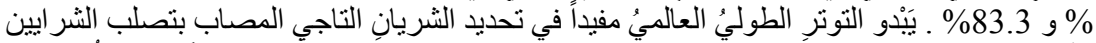

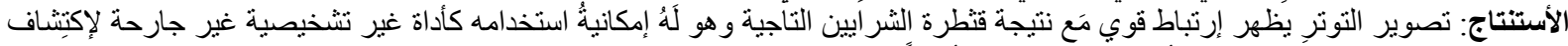

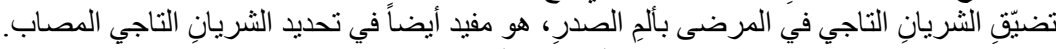

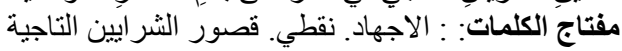

